\title{
Vegetarian diet as a risk factor for tuberculosis in immigrant south London Asians
}

\author{
D P Strachan, K J Powell, Aruna Thaker, F J C Millard, J D Maxwell
}

\begin{abstract}
Background - In a previous retrospective study of tuberculosis in south London among Asian immigrants from the Indian subcontinent Hindu Asians were found to have a significantly increased risk for tuberculosis compared with Muslims. This finding has been further investigated by examining the role of socioeconomic and lifestyle variables, including diet, as risk factors for tuberculosis in Asian immigrants from the Indian subcontinent resident in south London.

Methods - Using a case-control study technique Asian immigrants from the Indian subcontinent diagnosed with tuberculosis during the past 10 years and two Asian control groups (community and outpatient clinic controls) from the Indian subcontinent were investigated. Cases and community controls were approached by letter. A structured questionnaire concerning a range of demographic, migration, socioeconomic, dietary, and health topics was administered by a single trained interviewer to subjects (56 cases and 100 controls) who agreed to participate.
\end{abstract}

Results - The results confirmed earlier findings that Hindu Asians had an increased risk of tuberculosis compared with Muslims. However, further analysis revealed that religion had no independent influence after adjustment for vegetarianism (common among Hindu Asians). Unadjusted odds ratios for tuberculosis among vegetarians were $2 \cdot 7(95 \%$ CI $1 \cdot 1$ to 6.4 ) using community controls, and $4.3(95 \%$ CI 1.8 to 10.4$)$ using clinic controls. There was a trend of increasing risk of tuberculosis with decreasing frequency of meat or fish consumption. Lactovegetarians had an 8.5 fold risk $(95 \%$ CI 1.6 to 45.4 ) compared with daily meat/ fish eaters. Adjustment for a range of other socioeconomic, migration, and lifestyle variables made little difference to the relative risks derived using either community or clinic controls.

Conclusions - These results indicate that a vegetarian diet is an independent risk factor for tuberculosis in immigrant Asians. The mechanism is unexplained. However, vitamin D deficiency, common among vegetarian Asians in south London, is known to affect immunological competence. Decreased immunocompetence associated with a vegetarian diet might result in increased mycobacterial re- activation among Asians from the Indian subcontinent.

(Thorax 1995;50:175-180)

Keywords: tuberculosis, vegetarian diet, Asian immigrants.

In a previous retrospective study of 620 Asian immigrants from the Indian subcontinent with tuberculosis notified in south London between 1973 and 1988 we reported that Hindus had a significantly greater risk of developing tuberculosis than Muslims (overall Hindu:Muslim incidence ratio $4 \cdot 5$ ). The increased relative risk for Hindu Asians was similar for all sites (pulmonary $4 \cdot 9$, glandular $4 \cdot 0$, other sites $4 \cdot 3$ ). ${ }^{1}$

We speculated that the higher incidence of tuberculosis among Hindus might be due to vegetarianism (a dietary practice common amongst Hindus but not Muslims). However our initial study, based on retrospective analysis of patient data card files from the Wandsworth tuberculosis clinic, provided no information on dietary patterns. It was also limited by the difficulty in estimating the local populations of Hindus and Muslims from whom cases were drawn, and the indirect and unvalidated assessment of religious affiliation based on surname. Furthermore, we could not exclude the possibility that other factors such as socioeconomic status ${ }^{2}$ could have been responsible for the apparent difference between Hindu and Muslim Asians.

In order to validate the surname classification previously used to identify Hindu and Muslim subjects, to confirm the effect of religion using appropriate (population) controls, and to obtain dietary data, we conducted a case-control study of tuberculosis among immigrant Asians from the Indian subcontinent in south London.

\section{Methods}

SUBJECTS

Cases were selected from Asian patients attending the Wandsworth tuberculosis clinic within the last 10 years who had a diagnosis of active tuberculosis and had emigrated to the UK from the Indian subcontinent (India, Pakistan, Bangladesh, Sri Lanka) or East Africa. These included 77 cases notified during 1982-8 who were included in the previous study ${ }^{1}$ and 91 new cases notified during 1989-93.

A sample of potential community controls was drawn by selecting patients whose surname suggested they were from the Indian subcontinent who were registered with the general practitioner of each of the cases. Controls were chosen by a quota system from randomly 
chosen starting points in the record stack so that their distribution by date of birth (within decades) matched those of the cases (frequency matching). In all, 340 potential controls were drawn from 30 general practices.

The cases and potential community controls were classified as probably Hindu, Muslim, Sikh, or Christian in the same manner (using surname as a surrogate for religion) and by the same Asian dietician as in the previous study ${ }^{1}$ before establishing their actual religion at interview.

Cases and matched community controls were approached by letter (translated into five Asian languages) to arrange an interview in the home. After a single postal reminder and subsequent telephone contact, where possible, interviews were achieved with only 56 cases and 23 community controls. In view of the low response rate from controls, the remaining 205 community controls who had been selected were also contacted. In addition, a sample of clinic controls was recruited from Asian immigrants who were attending general medical, antenatal, and gynaecological outpatient clinics at St George's Hospital. Asian outpatients who were first generation immigrants from the Indian subcontinent were invited to take part in the questionnaire survey. They were unselected other than to ensure an age (deciles) and sex distribution comparable to the cases. The total number of controls interviewed was thus 100 , comprising 43 community controls and 57 clinic controls.

\section{QUESTIONNAIRE}

A structured questionnaire concerning a range of demographic, migration, socioeconomic, dietary, and health topics was administered by a single trained interviewer. Cases and controls were asked about their place of residence, family size, and socioeconomic circumstances as a child, prior to immigration, just after immigration, and currently. Religious affiliation, language of upbringing, date of arrival in the $\mathrm{UK}$, and frequency of subsequent visits to the tropics were noted. A food frequency questionnaire derived for Asian diets was used to record the frequency of consumption of 52 food items on a five point scale. Respondents who never ate meat or fish were classified as lactovegetarian. Tobacco and alcohol consumption were also recorded. The study was approved by the local research ethics committee.

Table 1 Religion (as imputed from surname) of recently diagnosed cases of tuberculosis, cases notified before 1989, community controls, and clinic controls

\begin{tabular}{|c|c|c|c|c|}
\hline \multirow[t]{2}{*}{ Religion } & \multicolumn{2}{|c|}{ Tuberculosis cases } & \multirow{2}{*}{$\begin{array}{l}\text { Selected community } \\
\text { controls }\end{array}$} & \multirow{2}{*}{$\begin{array}{l}\text { Outpatient clinic } \\
\text { controls }\end{array}$} \\
\hline & $\begin{array}{l}\text { Notified } \\
1973-88^{*}\end{array}$ & $\begin{array}{l}\text { Notified } \\
1989-93\end{array}$ & & \\
\hline $\begin{array}{l}\text { Hindu } \\
\text { Muslim } \\
\text { Other }\end{array}$ & $\begin{array}{c}420(68) \\
151(24) \\
49(8)\end{array}$ & $\begin{aligned} 61 & (67) \\
28 & (31) \\
2 & (2)\end{aligned}$ & $\begin{array}{c}141(41) \\
185(54) \\
14(4)\end{array}$ & $\begin{array}{c}25(44) \\
30(53) \\
2(4)\end{array}$ \\
\hline Total & $620(100)$ & $91(100)$ & $340(100)$ & $57(100)$ \\
\hline
\end{tabular}

* Included in the study reported in reference 1 .

Values in parentheses are percentages.

\section{STATISTICAL ANALYSIS}

Cases were compared with each of the two control groups separately using multiple logistic regression models fitted by the GLIM statistical package. ${ }^{3}$ Unconditional logistic regression was used because cases and controls were not individually matched. Adjustment for age at interview used 10 year age groups. Results are expressed as odds ratios (with $95 \%$ confidence intervals) for tuberculosis among Hindus compared with Muslims, and among vegetarians compared with non-vegetarians, after adjustment for potential confounding variables. Subjects belonging to other religious groups were assigned to a separate category in the regression models but odds ratios for this small group are not presented.

\section{Results}

VALIDATION OF SURNAME CLASSIFICATION

The religious affiliation derived from individual surnames before subsequent validation at interview of 156 subjects showed surname classification to be $93 \%$ accurate. The religion imputed from 70 of 75 distinct surnames verified at interview was correct; three names imputed as Hindu were of other religions (one Buddhist, one Christian, one Muslim) and two names imputed as Sikh were Hindu.

\section{CONFIRMATION OF EFFECT OF RELIGION}

The findings of our previous study were corroborated by comparing the 91 new cases recruited since the beginning of 1989 with all 340 selected community controls and 57 clinic controls. Table 1 shows the distribution of religions in each of these groups as imputed from surnames. The odds ratio for tuberculosis among presumed Hindus compared with presumed Muslims was 2.9 (95\% CI 1.7 to $4 \cdot 7$ ). This was little altered by adjustment for age and sex, and no significant interactions were found with age, sex, or site of tuberculosis.

Table 1 also shows, for comparison, the presumed religion of the 620 cases included in the first study. ${ }^{1}$ Comparing these with the 340 community controls, the Hindu:Muslim odds ratio is 3.6 (95\% CI 2.7 to 4.9$)$, similar to the incidence ratio previously estimated using assumptions about the Hindu:Muslim ratio in the local population derived from the Hindu: Muslim ratio in those attending the outpatient clinic. $^{1}$

\section{CHARACTERISTICS OF CASES AND CONTROLS} Cases and controls were well matched for countries of origin and year of arrival in the UK. The site of tuberculosis was pulmonary in 54\% and extrapulmonary in $46 \%$, most of whom ( $28 \%$ of all cases) had glandular tuberculosis.

The diagnosis of tuberculosis was confirmed by culture or direct smear in $34 \%$ of cases and by histological examination in $38 \%$. In the remaining cases tuberculosis was thought to be the most likely diagnosis on clinical grounds without bacteriological or histological confirmation. There was no substantial difference 
Table 2 Age, sex and religion (as imputed from surname) of cases and controls who were and were not interviewed

\begin{tabular}{|c|c|c|c|c|c|}
\hline & \multicolumn{2}{|c|}{ Tuberculosis cases } & \multicolumn{2}{|c|}{ Community controls } & \multirow[t]{2}{*}{ Clinic controls } \\
\hline & Interview & No interview & Interview & No interview & \\
\hline $\begin{array}{c}\text { Year of birth } \\
1903-39 \\
1940-54 \\
1955-73\end{array}$ & $\begin{array}{l}20(36) \\
14(25) \\
22(39)\end{array}$ & $\begin{array}{l}36(32) \\
35(31) \\
41(37)\end{array}$ & $\begin{array}{l}14(33) \\
16(37) \\
13(30)\end{array}$ & $\begin{array}{r}92(31) \\
99(33) \\
106(36)\end{array}$ & $\begin{array}{l}15(26) \\
23(40) \\
19(33)\end{array}$ \\
\hline $\begin{array}{l}\text { Sex } \\
\text { Male } \\
\text { Female }\end{array}$ & $\begin{array}{l}22(39) \\
34(61)\end{array}$ & $\begin{array}{l}53(47) \\
59(53)\end{array}$ & $\begin{array}{l}18(42) \\
25(58)\end{array}$ & $\begin{array}{l}159(54) \\
138(46)\end{array}$ & $\begin{array}{l}21(37) \\
36(63)\end{array}$ \\
\hline $\begin{array}{l}\text { Religion } \\
\text { Hindu } \\
\text { Muslim } \\
\text { Other }\end{array}$ & $\begin{array}{c}33(59) \\
20(36) \\
3(5)\end{array}$ & $\begin{array}{c}75(67) \\
37(33) \\
0(0)\end{array}$ & $\begin{array}{c}21(49) \\
19(44) \\
3(7)\end{array}$ & $\begin{array}{c}120(40) \\
166(56) \\
11(4)\end{array}$ & $\begin{array}{c}25(44) \\
30(53) \\
2(4)\end{array}$ \\
\hline Total & $56(100)$ & $112(100)$ & $43(100)$ & $297(100)$ & $57(100)$ \\
\hline
\end{tabular}

Values in parentheses are percentages.

Comparison of responders and non-responders confirms that no major bias has occurred by omission of the latter subjects from the analysis.

between the proportion of cases (23\%) and controls $(28 \%)$ who gave a history of close contact with another person with tuberculosis in the past five years. Two thirds of the cases (37/56) had last visited the tropics less than five years before notification. This compares with three quarters of the controls $(75 / 100)$ who had revisited the tropics within five years of the interview. A high proportion of the subjects ( $30 \%$ overall) did not know whether they had received BCG vaccination, but a positive history of vaccination was noted in $68 \%$ of cases and $52 \%$ of the controls.

Table 2 shows the characteristics of cases, clinic controls, and community controls who were and were not interviewed. Proportionately more women responded to the invitation to participate in the survey, but there was little variation with age. Hindu cases were less likely and Hindu controls were more likely to be interviewed. Thus, among the subsample of cases and community controls interviewed, the unadjusted Hindu:Muslim odds ratios for tuberculosis are smaller than those derived from the full sample of 91 cases and 340 community control subjects who were invited to take part in the study. The Hindu:Muslim odds ratio comparing interviewed cases with interviewed community controls was 1.5 (95\% CI 0.7 to $4 \cdot 4$ ), and $2 \cdot 0$ ( $95 \%$ CI 0.9 to $4 \cdot 3$ ) comparing interviewed cases with clinic controls.

Table 3 shows some of the characteristics of the subsample interviewed by religion and case or control status. Various indices of socioeconomic status showed that the respondents from this area of south London were not socially deprived: $56 \%$ had further education, $52 \%$ were currently employed in non-manual work themselves or were married to a non-manual worker, $80 \%$ lived in owner occupied housing, and $74 \%$ had access to one or more cars. These indicators of socioeconomic wellbeing did not vary consistently between Hindus, Muslims and other religions, and were similar in cases and controls (table 3). Socioeconomic status was not related to frequency of meat or fish consumption. Comparing the 44 vegetarians with the respondents who ate meat or fish 26 or more days each month, there were similar proportions in each group with further education ( $47 \% v 48 \%)$, non-manual occupations (44\% $v 50 \%$ ), owner-occupied housing (77\% $v 74 \%)$, and access to cars $(70 \% v 73 \%)$. The fathers of $77 \%$ of the vegetarians and $78 \%$ of the frequent meat eaters had been non-manual workers. Tobacco and alcohol consumption were uncommon. Among the 56 cases 18\% had ever smoked cigarettes compared with $20 \%$ of the 100 controls. The proportions drinking any alcohol were $11 \%$ and $15 \%$, respectively.

\section{DIET AND TUBERCULOSIS}

None of the cases were vegans - that is, avoided meat, fish, eggs, cheese or milk - but lactovegetarianism (avoidance of meat or fish) was common among Hindus, particularly among Hindu cases. All the Muslims interviewed were non-vegetarian (table 3). The odds ratios for tuberculosis among vegetarians compared with non-vegetarians are shown in table 4 . Before adjustment the odds ratios for tuberculosis among vegetarians were $2 \cdot 7(95 \%$ CI $1 \cdot 1$ to

Table 3 Socioeconomic characteristics and diet of respondents by religion and case/control status

\begin{tabular}{|c|c|c|c|c|c|c|}
\hline & \multirow{2}{*}{$\begin{array}{l}\text { Cases of } \\
\text { tuberculosis }\end{array}$} & \multirow{2}{*}{$\begin{array}{l}\text { Community } \\
\text { controls }\end{array}$} & \multirow[t]{2}{*}{ Clinic controls } & \multicolumn{3}{|c|}{ All groups combined* } \\
\hline & & & & Hindu & Muslim & Other \\
\hline \multicolumn{7}{|l|}{ Socioeconomic indicators } \\
\hline Father non-manual worker & $45(80)$ & $34(79)$ & $47(82)$ & $62(78)$ & $55(82)$ & $9(90)$ \\
\hline Further education & $32(57)$ & $23(53)$ & $32(56)$ & $46(58)$ & $33(49)$ & $8(80)$ \\
\hline \multicolumn{7}{|l|}{ Own or spouse's occupation } \\
\hline Non-manual & $27(48)$ & $26(60)$ & $28(49)$ & $42(53)$ & $31(46)$ & $8(80)$ \\
\hline Manual & $8(14)$ & $5(12)$ & $10(18)$ & $14(18)$ & $8(12)$ & $1(10)$ \\
\hline Nonet & $21(38)$ & $12(28)$ & $19(33)$ & $23(29)$ & $28(42)$ & $1(10)$ \\
\hline Rented housing & $11(20)$ & $2(5)$ & $18(32)$ & $16(20)$ & $14(21)$ & $1(10)$ \\
\hline Car ownership & $39(70)$ & $36(84)$ & $40(70)$ & $55(70)$ & $51(76)$ & $9(90)$ \\
\hline \multicolumn{7}{|l|}{ Meat and/or fish consumption } \\
\hline Daily & $3(5)$ & $4(9)$ & $8(14)$ & $2(3)$ & $12(18)$ & $1(10)$ \\
\hline $26-30$ days/month & $4(7)$ & $9(21)$ & $18(32)$ & $8(10)$ & $19(28)$ & $4(40)$ \\
\hline 21-25 days/month & $6(11)$ & $7(16)$ & $8(14)$ & $5(6)$ & $14(21)$ & $2(20)$ \\
\hline $16-20$ days/month & $13(23)$ & $8(19)$ & $10(17)$ & $9(11)$ & $20(30)$ & $2(20)$ \\
\hline $1-15$ days/month & $5(9)$ & $5(12)$ & $4(7)$ & $12(15)$ & $2(3)$ & $0(0)$ \\
\hline None (vegetarian) $\ddagger$ & $25(45)$ & $10(23)$ & $9(16)$ & $43(54)$ & $0(0)$ & $1(10)$ \\
\hline Number of respondents & $56(100)$ & $43(100)$ & $57(100)$ & $79(100)$ & $67(100)$ & $10(100)$ \\
\hline
\end{tabular}

Values in parentheses are percentages.

* Religion as determined at interview.

+ Retired or unemployed.

$\neq$ Includes one Hindu community control who was vegan.

Only a sample of information obtained from the questionnaire is shown. Further details of the characteristics of cases and controls, including migration history, can be obtained on request from the authors. 
Table 4 Odds ratios (95\% confidence intervals) for tuberculosis among vegetarians compared with non-vegetarians before and after adjustment for various factors

\begin{tabular}{|c|c|c|c|c|}
\hline \multirow[t]{2}{*}{ Odds ratio adjusted for } & \multicolumn{2}{|c|}{ Cases $v$ community controls } & \multicolumn{2}{|l|}{ Cases $v$ clinic controls } \\
\hline & Odds ratio $(95 \% \mathrm{CI})$ & $\chi^{2}(1 d f)$ & Odds ratio $(95 \% \mathrm{CI})$ & $\chi^{2}(1 d f)$ \\
\hline Nothing & $2 \cdot 7(1 \cdot 1$ to $6 \cdot 4)$ & $4.99 *$ & $4.3(1.8$ to 10.4$)$ & $11 \cdot 5^{* * *}$ \\
\hline Age and sex & $2.8(1.2$ to 7.0$)$ & $5.44^{*}$ & $4.5(1.8$ to 11.0$)$ & $11 \cdot 9 * * *$ \\
\hline Age, sex, and religion & $3.1(1.0$ to $9 \cdot 7)$ & $3 \cdot 78$ & $5 \cdot 2(1.7$ to $15 \cdot 9)$ & $8 \cdot 7^{* *}$ \\
\hline $\begin{array}{l}\text { Age, sex, educational level, housing tenure, } \\
\text { and car ownership }\end{array}$ & $2 \cdot 9(1 \cdot 1$ to $7 \cdot 8)$ & $4 \cdot 94^{*}$ & $5 \cdot 2(2 \cdot 0$ to $13 \cdot 3)$ & $13 \cdot 1^{* * *}$ \\
\hline $\begin{array}{l}\text { Age, sex, smoking history, and alcohol } \\
\text { consumption }\end{array}$ & $2.5(1.0$ to 6.4$)$ & $4 \cdot 08^{*}$ & $4.6(1.9$ to 11.4$)$ & $12 \cdot 1^{* * *}$ \\
\hline
\end{tabular}

6.4) using the community controls and $4 \cdot 3$ ( $95 \%$ CI $1 \cdot 8$ to $10 \cdot 4$ ) using the clinic controls. Adjustment for these crude odds ratios for a range of potentially confounding variables (including measures of socioeconomic status, sex, marital, and employment status, smoking and alcohol consumption, country of origin, migration data, and history of contact with tuberculosis) made little difference to the point estimates derived using either community controls or clinic controls. The association of vegetarianism with tuberculosis was independent of religion, but there was no independent influence of religion after adjustment for vegetariansim (adjusted Hindu:Muslim odds ratios: 0.8 (95\% CI 0.3 to 2.4 ) for cases versus community controls, and 0.9 (95\% CI 0.3 to $2 \cdot 4$ ) for cases versus clinic controls).

Among non-vegetarians there was a tendency for cases with tuberculosis to eat meat and/or fish less frequently than controls (table 3 ). After adjustment for age, sex and religion, the trend in the risk of tuberculosis across all categories of meat/fish consumption (including vegetarians) was significant both for cases versus community controls $\left(\chi^{2}=5 \cdot 00, \mathrm{df}=1, \mathrm{p}=0 \cdot 02\right)$ and for cases versus clinic controls $\left(\chi^{2}=17 \cdot 9, \mathrm{df}=1\right.$, $\mathrm{p}<0.0001)$. The corresponding adjusted odds ratios for different categories of meat/fish consumption relative to subjects eating meat/fish daily are shown in the figure. These estimates

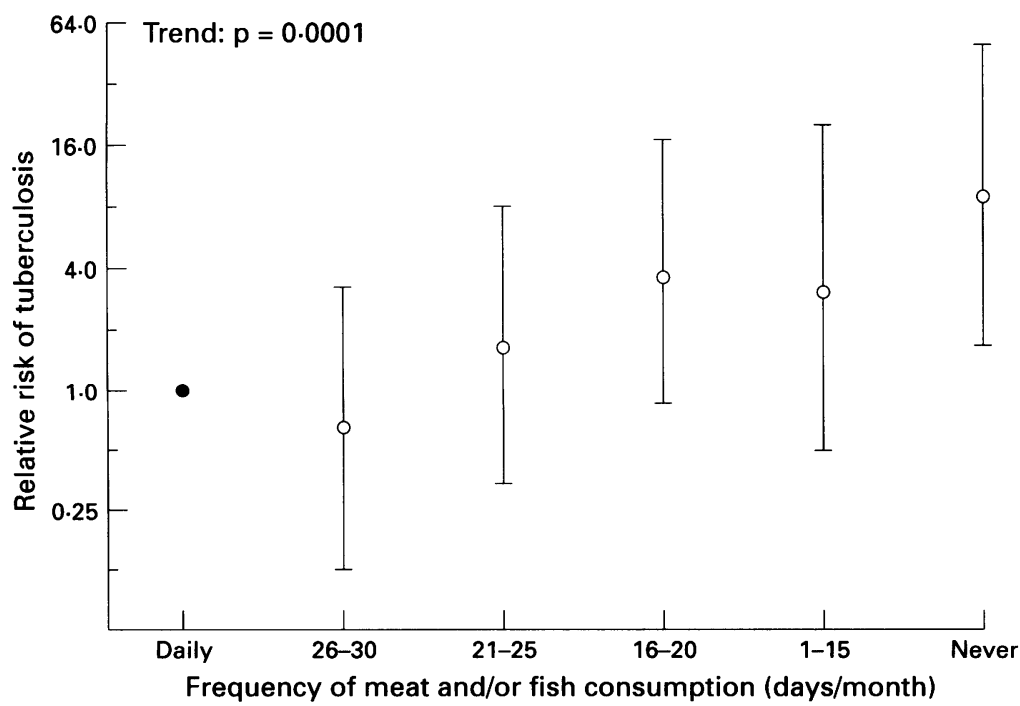

Odds ratios (adjusted for age, sex and religion) for tuberculosis in subjects with different levels of meat and/or fish consumption. Odds ratios are derived using both control groups combined. Point estimates are shown relative to daily consumption of meat and/or fish as baseline. Error bars denote $95 \%$ confidence intervals. Note that the vertical axis is logarithmic. were based on comparison of cases with both control groups combined. Tests for trend were highly significant whether vegetarians were included $\left(\chi^{2}=15 \cdot 1, \mathrm{df}=1, \mathrm{p}=0.0001\right)$ or $\mathrm{ex}-$ cluded $\left(\chi^{2}=6.84, \mathrm{df}=1, \mathrm{p}<0.01\right)$ from the trend analysis. The odds ratio for tuberculosis among vegetarians compared with daily meat/ fish eaters in this combined analysis was 8.5 (95\% CI 1.6 to $45 \cdot 4)$.

\section{Discussion}

As a result of immigration about $2 \cdot 5 \%$ of UK residents are now of south Asian or Indian subcontinent origin. ${ }^{4}$ However, national surveys of tuberculosis notification have shown that over a third of new cases in England and Wales were in people from the Indian subcontinent, and that immigrant Asians have a 30-40 times greater risk of developing tuberculosis than the indigenous population. ${ }^{56}$

The present study has confirmed that surname analysis is a reliable method for determining religion among Asians from the Indian subcontinent. Using a fresh series of 91 patients and a large sample of community controls, which together effectively rule out chance and selection bias, we confirmed our previous finding that Hindu Asians are at significantly greater risk of developing tuberculosis than other groups of Indian subcontinent origin living in south London. ${ }^{1}$ A recent retrospective study from Leicester on abdominal tuberculosis also demonstrated an increased risk in Hindu Asians (relative risk $=2 \cdot 3$ ). ${ }^{7}$

The low response rate in our community controls was possibly because our original invitations were explicit about the role of the survey in investigating tuberculosis, a disorder which still carries a considerable stigma. Hindu cases were less likely to respond than Muslim cases, while Hindu controls were more likely than Muslims to agree to an interview (table 2). Our study was therefore biased against finding a relationship between tuberculosis and Hinduism or vegetarianism. Nevertheless, Hindu religion again emerged as a significant risk factor for tuberculosis, but further analysis indicated that religion per se had no independent effect.

Vegetarian diet (a traditional feature of Hindu culture) emerged as a significant independent risk factor for tuberculosis and appeared to be the main explanation for the Hindu excess. The finding of a substantial dose response effect, with decreasing susceptibility to tuberculosis amongst non-vegetarian im- 
migrant Asians who eat meat or fish more frequently, suggests that this may be a causal relationship. The findings of our study are supported by the results of a postal survey of Asians in north London which showed that the prevalence of tuberculosis was $2 \cdot 8$ times higher among strict vegetarians than among those taking a mixed diet. ${ }^{8}$ It is likely that many Asian immigrants originating from the Indian subcontinent or East Africa where tuberculosis is endemic harbour small numbers of $\mathrm{Myco}-$ bacterium tuberculosis (persistor status). ${ }^{9}$ The pattern of tuberculosis seen in immigrant Asians in the UK, with frequent glandular and non-pulmonary involvement, is well described ${ }^{5}$ and has similarities to the pattern of tuberculosis seen in AIDS. ${ }^{10}$

The suggestion that tuberculosis in some Asian patients from the Indian subcontinent might have been contracted after a return visit to the tropics ${ }^{11}$ cannot be excluded, but fewer cases had revisited the tropics in the five years before notification than had controls in the five years before their interview. Moreover, a history of close contact with tuberculosis in the UK or the tropics was no more common among our cases than the controls, lending further support to our hypothesis that tuberculosis in many immigrant Asians is a consequence of reactivation due to decreased immunocompetence associated with infrequent meat or fish consumption. Tuberculosis may develop many years after immigration (two thirds of the cases in the present study were notified more than five years after arrival in the UK) but our previous retrospective review of 620 cases of Asian tuberculosis in south London, as well as national surveys, ${ }^{1}$ have shown that the highest rates of tuberculosis in Asians from the Indian subcontinent occur about five years after immigration. Adjustment for country of origin and year of arrival in the UK has been included in the analyses in table 4 and makes little difference to the increased risk of tuberculosis among vegetarians. Tuberculosis remains a major public health problem in the developing world and may be increasing in western industrialised nations. It has been estimated that one third of the world's population is infected without overt disease (persistor status), and that reactivation in these individuals contributes to 8-10 million cases annually, resulting in three million deaths. ${ }^{1213}$

The rapid decline in tuberculosis notifications and deaths in the UK since the 19th century, which predated effective drug therapy, has been attributed to improved socioeconomic circumstances, including better housing and nutrition. Tuberculosis remains a well recognised problem in impoverished homeless people, but the separate contributions of poverty, malnutrition, overcrowding, and alcohol abuse are difficult to determine. ${ }^{213}$ Our casecontrol study took particular care to examine the possible confounding effects of life style and socioeconomic status, but no differences were seen between Asian cases and controls for a variety of indices. Alcohol consumption was rare, and both cases and controls appeared to be from an economically privileged section of the community, in keeping with a recent national housing and dwelling survey. ${ }^{14}$

Cell mediated immunity is crucial to the host response to infection with Mycobacterium tuberculosis. ${ }^{15}{ }^{16}$ Reduced CD4 inducer/helper T lymphocyte numbers in AIDS explains why these patients are at substantially increased risk of developing tuberculosis. However, disturbance of the persistor status with reactivity and development of overt tuberculosis is not well understood in most cases that are not associated with HIV infection or immunosuppressive drug therapy. ${ }^{9}$

Malnutrition is known to suppress immunity. ${ }^{17}$ Studies have shown that supplementation of elderly subjects with multiple vitamins and trace elements significantly improved a number of markers of immunocompetence and decreased the duration of acute infectious illness. ${ }^{18}$ Why a vegetarian diet should enhance the risk of tuberculosis in immigrant Asians is as yet unexplained, but it may be due to impairment of immunocompetence as a consequence of associated micronutrient deficiency. It is of interest that vegetarian diets appear to be effective in the treatment of rheumatoid arthritis. ${ }^{19}$ The mechanism is unknown but it was speculated that an effect on immunological function may be mediated through a change in the profile of fatty acids of serum phospholipid which occur on a vegetarian diet, since dietary fatty acids can modulate the inflammatory process in rheumatoid arthritis. ${ }^{20}$ Other well recognised effects of an Asian vegetarian diet, particularly in vegans, include deficiencies of iron, cobalamin (vitamin $B_{12}$ ), and vitamin $D .{ }^{21-23}$ In vitro studies have shown impaired neutrophil function in cobalamin depleted individuals. ${ }^{24}$ However, macrophages and lymphocytes, rather than neutrophils, are concerned in cell mediated host defence against mycobacteria. ${ }^{1516}$ There is good animal experimental evidence in vitro and in vivo for an immunoregulatory role for 1,25-dihydroxyvitamin $\mathrm{D}$ in both lymphocytes and monocytes ${ }^{2526}$ which has led to speculation about a possible link between vitamin $\mathrm{D}$ deficiency and impaired host defence to human Mycobacterium tuberculosis. ${ }^{27}$ The active form of vitamin $\mathrm{D}$ modulates the proliferation, differentiation, and immune function of these cells, but the pathophysiological implications of these properties of vitamin $\mathrm{D}$ have yet to be established in a clinical context. Although vitamin D stores are largely determined by photosynthesis, previous studies have confirmed that vegetarian Asians in south London are at much greater risk of developing clinical and biochemical vitamin $\mathrm{D}$ deficiency than nonvegetarian Asians. ${ }^{222328}$ An increasingly strict vegetarian diet increased the risk of osteomalacia in a dose-dependent manner. ${ }^{23}$

The identification of a vegetarian diet as a risk factor for tuberculosis may provide additional insights into the role of nutrition in cell mediated immunity and, more specifically, a better understanding of the pathophysiology of mycobacterial reactivation. These findings may be relevant to other diseases where cell mediated 
immunity is important. Further epidemiological and clinical research is required to confirm our findings and to clarify the role of specific nutrients. However, if the reactivation of tuberculosis is influenced by single or multiple vitamin deficiencies, our findings would have important implications for the prevention of one of the world's most serious infectious diseases.

We thank Mrs Maureen Malone for identifying case records from the Wandsworth tuberculosis clinic and are grateful for the cooperation of local general practitioners in recruiting the community controls. The study was supported in part by a grant from the South West Thames Regional Research Committee.

1 Finch PJ, Millard FJC, Maxwell JD. Risk of tuberculosis in immigrant Asians: culturally acquired immunodeficiency? Thorax 1991;46:1-5.

2 Spence DS, Hotchkiss J, Williams CSD, Davies PDO Tuberculosis and poverty. BMF 1993;307:759-61.

3 Baker RJ, Nelder JA. The GLIM system manual, release 3. Oxford: Numerical Algorithms Group, 1978

4 Ahmad WIU, Kernohan EEM, Baker MR. Health of British Asians: a research review. Commun Med 1989;11:49-56.

5 National survey of tuberculosis notifications in England and Wales in 1983: characteristics of disease. Tubercle 1987; 68:19-32.

6 Meredith SK, Aber VR, Nunn AJ, Byfield SP, Johnson DA Darbyshire $\mathrm{JH}$, et al. National survey of notifications of tuberculosis in England and Wales in 1988. Thorax 1922; 47:770-5.

7 Probert CSJ, Jayanthi V, Wicks AC, Carr-Locke DL, Garner $P$, Mayberry JF. Epidemiological study of abdominal tuberculosis among Indian immigrants and the indigenous population of Leicester, 1972-1989. Gut 1992;33:1085-8.

8 Chanarin I, Stephenson E. Vegetarian diet and cobalamin deficiency: their association with tuberculosis. $\mathrm{F}$ Clin Pathol 1988;41:759-62.

9 Grange JM. The mystery of the mycobacterial persistor Tubercle Lung Dis 1992;73:249-51.

10 Harries AD. Tuberculosis and human immunodeficiency virus infection in developing countries. Lancet 1990;335: 387-90.
11 McCarthy OR. Asian immigrant tuberculosis - the effect of visiting Asia. $\mathrm{Br} \mathcal{F}$ Dis Chest 1984;78:248.

12 Burden of tuberculosis world wide. Lancet 1992;340:1403.

3 Watson JM. Tuberculosis in Britain today. BMF 1993;306: 221-2.

14 Department of the Environment. National housing and dwellings survey. London: HMSO, 1978.

15 Rook GAW. Role of activated macrophages in the immunopathology of tuberculosis. Br Med Bull 1988;44: 611-23.

16 Lowrie DB, Andrew PW. Macrophage antimycobacterial mechanisms. Br Med Bull 1988;44:624-34.

17 Good RA. Nutrition and immunity. $\mathcal{F}$ Clin Immunol 1981; 1:3-11.

18 Chandra RK. Effect of vitamin and trace-element supplementation on immune responses and infection in elderly subjects. Lancet 1992;340:1124-7.

19 Kjeldsen-Kragh J, Haugen M, Borchgrevink CF, Laerum E, Eek M, Mowinkel P, et al. Controlled trial of fasting and one-year vegetarian diet in rheumatoid arthritis. Lancet and one-year vegetariar

20 Kremer JM, Lawrence DA, Jubiz W, DiGiacoma R, Rynes $\mathrm{R}$, Bartholomew LE, et al. Dietary fish oil and olive oil supplementation in patients with rheumatoid arthritis. 33:810-20.

21 Chanarin I, Malkowska V, O'Hea A-M, Rinsler MG, Price AB. Megaloblastic anaemia in a vegetarian community. Lancet 1985; ii:1168-72.

22 Peach H, Compston JE, Vedi S. Value of the history in diagnosis of histological osteomalacia among Asians presenting to the NHS, Lancet 1983;ii:1347-9.

23 Finch PJ, Ang L, Eastwood JB, Maxwell JD. Clinical and histological spectrum of osteomalacia among Asians in south London. $O f$ Med 1992;NS83:439-48.

24 Skacel PO, Chanarin I. Impaired chemiluminescence and bacterial killing by neutrophils from patients with severe cobalamin deficiency. Br f Haematol 1983;55:203-15.

25 Manolagas SC, Hustymer FG, Yu XP. 1, 25-Dihydroxyvitamin $\mathrm{D}_{3}$ and the immune system. Proc Soc Exp Biol Med 1989;191:239-45.

26 Yang S, Smith C, Prahl JM, Luo X, DeLuca HF. Vitamin $D$ deficiency suppresses cell-mediated immunity in vivo. Arch Biochem Biophys 1993;303:98-106.

27 Davies PDO. A possible link between vitamin D deficiency and impaired host defence to Mycobacterium tuberculosis. Tubercle 1985;66:301-4.

28 Finch PJ, Ang L, Colston KW, Nisbet J, Maxwell JD. Blunted seasonal variation in serum 25-hydroxyvitamin $\mathrm{D}$ and increased risk of osteomalacia in London Asians. Eur 7 Clin Nutr 1992;46:509-15. 